\title{
Desenvolvimento, evidências psicométricas e invariância da escala de sentimento de culpa do Consumo (ESCC) em mães brasileiras
}

\author{
Development, psychometric evidence and invariance of the consumer guilt scale (ESCC) in
}

\section{Brazilian mothers}

Desarrollo, evidencia psicométrica e invariancia de la escala de culpa del consumidor (ESCC) en madres brasileñas

\section{Resumo}

Este artigo tem como objetivo o desenvolvimento e validação de uma escala sobre o sentimento de culpa materna referente ao consumo e seu correlato com a autoestima. O tema da culpa tem sido estuda na ciência humana e social contribuindo para uma avaliação psicossocial ou desenvolvimento psicológico em termo da estrutura e organização emocional da pessoa frente ao desejo de consumo. Desta maneira, com foco no tema do comportamento do consumidor, avalia-se o quanto as mães se sentem culpadas por atender ou não ao pedido de compra de seus filhos, permitindo com isso, apresentar uma medida de avaliação psicológica ainda escassa no contexto brasileiro. Participaram do estudo 606 mães, com filhos acima de 8 anos, distribuídos em três amostra por todo o Brasil. Elas responderam a escala de sentimento de culpa frente ao consumo para os filhos, escala de autoestima e dados sociodemográficos. Observou-se que as escala não apenas é confiável, mas, que é possível avaliar duas dimensões de culpa da mãe: sentimento de culpa por desajuste de ego e impulsividade e sentimento de culpa catártica/não consciente. De forma geral, evidenciaram-se a qualidade de uma medida sobre sentimento de culpa no consumo 
destinados aos filhos, bem como, que é possível utilizar tal medida para contextos terapêuticos e sociais quando se pretender avaliar comportamento materno de consumo.

Palavras-chave: Mãe; Escala; Validade; Culpa; Consumo.

\begin{abstract}
This article aims to develop and validate a scale on the maternal guilt regarding consumption and its correlation with self-esteem. The guilt theme has been studied in human and social science contributing to a psychosocial assessment or psychological development in terms of the person's emotional structure and organization in the face of the desire to consume. In this way, focusing on the topic of consumer behavior, it is evaluated how much the mothers feel guilty for meeting or not complying with their children's purchase order, thus allowing them to present a measure of psychological evaluation that is still scarce in the Brazilian context. 606 mothers, with children over 8 years old, participated in the study, distributed in three samples throughout Brazil. They answered the scale of guilt towards consumption for their children, self-esteem scale and sociodemographic data. It was observed that the scale is not only reliable, but that it is possible to evaluate two dimensions of the mother's guilt: feeling of guilt due to ego mismatch and impulsivity and feeling of cathartic / unconscious guilt. In general, the quality of a measure about guilt in consumption for children was evidenced, as well as, that it is possible to use such measure for therapeutic and social contexts when it is intended to assess maternal consumption behavior.
\end{abstract}

Keywords: Mother; Scale; Validity; Fault; Consumption.

\title{
Resumen:
}

Este artículo tiene como objetivo desarrollar y validar una escala sobre el sentimiento de culpa materna relacionado con el consumo y su correlación con la autoestima. El tema de la culpa ha sido estudiado en las ciencias humanas y sociales contribuyendo a una evaluación psicosocial o desarrollo psicológico en términos de la estructura y organización emocional de la persona frente al deseo de consumir. De esta manera, enfocándose en el tema del comportamiento del consumidor, se evalúa cuánto se sienten culpables las madres por cumplir o no cumplir con la orden de compra de sus hijos, lo que les permite presentar una medida de evaluación psicológica que aún es escasa en el contexto brasileño. En el estudio participaron 606 madres, con hijos mayores de 8 años, distribuidas en tres muestras en todo Brasil. Respondieron a la escala de sentimientos de culpa hacia el consumo de sus hijos, escala de autoestima y datos sociodemográficos. Se observó que la escala no solo es confiable, sino que es posible evaluar dos dimensiones de la culpa de la madre: sentimiento de culpa por desajuste del ego e impulsividad y sentimiento de culpa catártico / inconsciente. En general, se evidenció la calidad de una medida de culpabilidad en el consumo de los niños, así como que es posible utilizar dicha medida para contextos terapéuticos y sociales cuando se pretende evaluar el comportamiento de consumo materno.

Palabras clave: Madre; Escala; Validez; Falla; Consumo.

\section{Introdução}

Atualmente, é bem comum deparar-se com mulheres na busca de conquistar a independência pessoal, social e profissional, rompendo com as barreiras impostas socialmente impostas pela sociedade. Tal temática traz conduz a inúmeros questionamentos quanto ao direito das mulheres, bem como, os maiores desafios que a mulher enfrenta, um destes, refere-se à condição da maternidade (Tourinho, 2006).

Em todo o desenvolvimento teórica da ciência psicológica, é possível perceber que uma ausência, quanto a problematização da construção cultural da maternidade e do (des)encontro das mulheres com ela (Zanello, 2016). Esta condição, em sua maioria, associa a sua decisão em ser mãe a escolha pela profissão, ao tempo que passa solteira, a demora em relacionar-se a um companheiro, entre outras situações. De acordo com Tourinho (2006), tais condições são consideradas uma espécie de fórmulas ou padrões 'prontos', os quais, esperam funcionar, de forma igualitária para todas as mulheres.

O fato é que, na concepção de Neder (2016), depois que a mulher se torna mãe, há uma cobrança em torno dessa condição, especialmente, no que diz respeito ao ideal do ser mães, quanto ao ser uma pessoa que se dedicará integralmente as necessidades de seu filho, devendo assumir, praticamente, a maternidade quanto vocação materna, instintiva e obrigatória da e para a mulher; de acordo com a autora supracitada, parece não existir uma alternativa para mulher se esta não se tornasse mãe. Assim considerado, tal cobrança acarreta muitos conflitos para a mulher e, provavelmente, geraria insegurança e sentimentos negativos, entre eles a culpa (cf. Arteiro, 2017). 
Em termos gerais, a culpa é estudada e discutida nas mais diversas áreas de conhecimento da ciência humana e social contribuindo para a sociedade quanto interpretação de um construto que desperta o interesse da pesquisa seja quanto avaliação psicossocial ou desenvolvimento psicológico (Erikson, 1976a, 1976b; Ghingold, 1981; Winnicott, 1994, 1999).

Sendo assim, a relação entre a responsabilidade e a culpa é, pois, considerada uma temática que já é discutida na psicologia, trazendo diferentes contribuições. Com o passar dos anos o sentimento de culpa foi sendo estudado por outras áreas da psicologia, buscando um significado para esse sentimento que, cada vez mais, tem feito parte da sociedade e que hoje acomete muitas mães, afinal quem nunca escutou o ditado popular que diz: nasce uma mãe e com ela, vem a culpa (Lima, 2012).

Com isso, na busca de se livrar (ou negar) essa culpa, algumas mães acabam se rendendo ao consumo, na tentativa de compensar algo ou até mesmo se sentir melhor através do consumo (Lascu, 1991). E quando o assunto é consumo, a maternidade ganha um espaço para muitas reflexões teóricas e práticas.

Desta maneira, no contexto do consumo e a relação com o ser mãe, desde a arrumação do quarto, compra de enxoval etc., o fator compra, ganha prioridade. Os pais (especialmente, a mãe), por sua vez, procuram oferecer o melhor, independente da classe social, condição essa, que, na maioria das vezes, é causa de endividamento, justamente, por manter, apenas uma espécie de acúmulos de produtos para o filho, que algumas não chegam a usar de fato (Pontes, 2012; Arteiro, 2017).

Para Lascu (1991; Alexandre \& Coluci, 2011), a culpa passou a receber interesse da literatura científica em comportamento do consumidor, no começo da década de 90, quando começou a se perceber, através de pesquisas, que esse sentimento poderia influenciava no consumo. Iniciando-se, então, a se estudar na área de comportamento do consumidor, como o sentimento de culpa pode influenciar no consumo, despertando o interesse de mais estudos que abordassem a relação culpa e consumo.

Nesse sentido, a psicologia, por ser uma área de atuação que lida com todas as facetas relativas à construção do sujeito, começou a contribuir nessa linha de pesquisa a fim de entender melhor o sentimento de culpa frente ao consumo e ajudar a desenvolver estratégias de marketing para impulsionar vendas (Lima, 2012).

A partir deste contexto, a escolha da abordagem do tema desse artigo ocorreu mediante a necessidade de se desenvolver uma escala que possa contribuir na área da psicologia, bem como, às mães que se sentem culpadas frente ao consumo. Em pesquisa nas base de dados da produção científica brasileiro, apenas o artigo de Formiga, Castro, Gadelha e Pimentel (2020), avaliando o conteúdo da escala sobre o sentimento de culpa materna em relação ao consumo, tratou deste tema. De acordo com os autores supracitados, as análises estatísticas revelaram a qualidade e segurança no conteúdo de cada item, porém, não revelou qual seria a organização fatorial do construto. Com isso, tanto por existir apenas uma escala específica sobre o tema em questão, quanto poucas pesquisas e instrumentos capaz de mensurar e identificar essa culpa, com foco na análise de construto a ser verificada para as mães é que, o objetivo principal deste estudo, trata-se de construir, validar e verificar a invariância fatorial em distintas amostras.

\section{Metodologia}

\section{Amostra}

Tratou-se de uma pesquisa quantitativa, do tipo descritivo, exploratório e correlacional, envolvendo mães em todo o Brasil. A amostra referente foi avaliada através do pacote estatístico G Power 3.1, software, o qual, é utilizado para calcular o poder estatístico relacionando o ' $n$ ' necessário para a pesquisa e tipo de cálculo a ser realizado (Faul, Erdfelder, Lang, \& Buchner, 2007). Considerou-se uma probabilidade de $95 \%$ ( $\mathrm{p}<0,05)$, magnitude do efeito amostral $(\mathrm{r} \geq 0,50)$ e um padrão de poder hipotético $(\pi \geq 0,80)$ destinada verificação da qualidade e significância da amostra para a a realização da pesquisa. 
A coleta de dados foi realizada através do método bola de neve, pois, avaliou-se a disponibilidade e interesse do respondente, em participar da pesquisa, isto é, as mães. A partir dos critérios estabelecidos no Gpower, obteve-se uma amostra total de 606 mães, distribuídas em três amostras, destinadas a avaliação da análise fatorial exploratória, análise fatorial confirmatória e análise de convergência e divergência foram coletadas, a primeira (N1) com com 202 mães, a segunda amostra (N2), com 203 mães e a terceira amostra (N3) de com 201 mães em todo o Brasil.

Estas apresentaram os seguintes indicadores estatísticos, no que se refere a qualidade da amostra para a presente pesquisa: $\mathrm{N} 1=\mathrm{t} \geq 1,98 ; \pi \geq 0,96, \mathrm{~N} 2=\mathrm{t} \geq 1,98 ; \pi \geq 0,95$ e N3 $=\mathrm{t} \geq 1,98 ; \pi \geq 0,96$ ambas, apresentaram um $\mathrm{p}<0,05$. Esta condição revelou que as amostras não somente são suficientes para a realização do estudo em questão, mas, também, que é possivel a realização dos calculos estatísticos exigidos relacionados ao objetivo deste estudo. Quanto ao critério de inclusão considerou-se: ser mãe com mais de 4 anos, ter idade acima de 18 anos e estar disponível para responder ao questionário.

\section{Instrumentos}

As participantes responderam um questionário contento:

Escala de Sentimento de Culpa do Consumo (versão Mãe): Trata-se de uma escala desenvolvida pelos autores do artigo, que tem, por sua vez, o objetivo de avaliar o sentimento de culpa das mães frente ao consumo. A escala é composta por 17 itens, os quais, relatam o sentimento que a consumidora (todas mães) expressa quando dirige-se as compras para o (s) e/ou a (s) filho (o) (a) (s), devido ao pouco tempo na diversão ou atenção familiar que destinou a eles [por exemplo, 1.Sinto-me culpada por comprar objetos que meu (minha) filho (a) não precisa; 2.Sinto culpa quando desejo comprar para meu (minha) filho (a); 3.Sinto-me culpada quando tenho inveja das compras que meus parentes e/ou amigos muito íntimos fazem para seu (sua) filho (a)].

A respondente deveria indicar numa escala do tipo Likert, de 6 pontos, variando de $0=$ Pouco a $5=$ Muito, o quanto ela experimentou cada uma das questões na sua vida com relação aos filhos. No estudo desenvolvido por Formiga, Castro, Gadelha e Pimentel (2020) a respeito da análise de conteúdo desta escala, estes autores observaram a qualidade e segurança no conteúdo expresso dos itens na concepção dos respondentes; isto é, tanto a discriminação quanto a representatividade do conteúdo dos itens revelaram a existência de validade do conteúdo do construto em mães, garantindo a administração desta medida em mães.

Além desse instrumento, um questionário com a caracterização sociodemográfica foi incluído (aspectos relacionados a sexo, idade, renda econômica, nível educacional).

\section{Administração da pesquisa e análise de dados}

Todos os procedimentos adotados, nesta pesquisa, seguiram as orientações previstas na Resolução 466/2012 do CNS e na Resolução 016/2000 do Conselho Federal de Psicologia para as pesquisas com seres humanos (Conselho Nacional de Saúde [CNS], 2012; Associação Nacional de Pesquisa e Pós-Graduação em Psicologia [ANPEPP], 2000).

Após a submissão e aprovação do problema realizada pelo conselho de ética da Plataforma Brasil submetido ao CONEP sob o protocolo de pesquisa CAAE $n^{\circ}$ 21345019.9.0000.5537, o instrumento da pesquisa foi aplicado as mães de forma individual, através de um formulário eletrônico hospedado no google.docs. De acordo com a disponibilidade do tempo e espaço físico das respondentes em seu espaço familiar ou laboral, esta, foi convidada a participar de forma voluntária, anônima e privada em responder o questionário.

Para isso, foi encaminhado para o e-mail, telefone particular (através das redes sociais que eles pudessem fazer parte) e nas redes sociais o link da pesquisa. Foi informado as respondentes que desejavam participar, quando acessaram o endereço 
da pesquisa, que a pesquisa será anônima e sigilosa, podendo desistir a qualquer momento, sem prejuízo algum para ele ou para o pesquisador.

Desta forma, para aplicação do instrumento, um pesquisador (com experiência prévia na pesquisa), ficou disponível, no e-mail e telefone celular, durante todo o momento da aplicação do instrumento, condição essa que tinha como referência, esclarecer as dúvidas e possíveis incompreensões do instrumento. Um tempo médio de 25 minutos foi suficiente para a conclusão das respostas no instrumento.

Em relação a análise dos dados, utilizar-se-á o pacote estatístico SPSSWIN, em sua versão 24.0, para tabular os dados e realizar as análises estatísticas descritivas (média e desvio padrão), teste t de Student e correlação de Pearson destinada, respectivamente, a discriminação dos itens e representatividade de conteúdo da escala.

No mesmo pacote estatístico, realizou-se a análise de Componentes Principais (CP), tomando como critérios para decisão fatorial, o KMO igual ou superior a 0,70 e o Teste de Esfericidade de Bartlett (qui-quadrado, $\chi^{2}$ ) significativo ( $p<$ 0,05) (Tabachnick \& Fidell, 2001; Dancey \& Reidy, 2006); considerou-se ainda, os critérios de Kaiser (valor próprio igual ou superior a 1) e Cattell (distribuição gráfica dos valores próprios, visando distinguir aqueles sobressalentes) e análise Paralela (Dancey \& Reidy, 2006; Ledesma \& Valero-Mora, 2007).

Após essas análises, realizou-se uma análise fatorial confirmatória; esta última, tinha o objetivo de avaliar se o modelo bidimensional obliquo, previamente encontrado por esses autores, ainda apresentaria indicadores aceitáveis quanto a sua estrutura fatorial, principalmente, quando compará-lo ao modelo unifatorial e o bifatorial ortogonal.

Considerou-se a matriz de covariâncias, como entrada da fatorialização, adotando o estimador $M L$ (Maximum Likelihood). Sendo um tipo de análise estatística mais criteriosa e rigorosa, testou-se a estrutura teórica que se propõe neste estudo: isto é, a estrutura com quatro fatores. Esta análise apresenta alguns índices que permitem avaliar a qualidade de ajuste do modelo proposto (Byrne, Shavelson, \& Muthén, 1989; Hair, Tatham, Anderson, \& Black, 2005; Kelloway, 1998; Tabachnick, \& Fidell, 1996; Van De Vijver, \& Leung, 1997). A seguir serão apresentados esses indicadores:

- O $\chi^{2}$ (qui-quadrado) testa a probabilidade do modelo teórico se ajustar aos dados: quanto maior o valor do $\chi^{2}$ pior o ajustamento. Entretanto, ele tem sido pouco empregado na literatura, sendo mais comum considerar sua razão em relação aos graus de liberdade ( $\chi^{2} /$ g.l.). Neste caso, valores até 3 indicam um ajustamento adequado.

- Raiz Quadrada Média Residual (RMR), que indica o ajustamento do modelo teórico aos dados, na medida em que a diferença entre os dois se aproxima de zero.

- O Goodness-of-Fit Index (GFI) e o Adjusted Goodness-of-Fit Index (AGFI) são análogos ao $R^{2}$ na regressão múltipla e, portanto, indicam a proporção de variância-covariância nos dados explicada pelo modelo. Os valores desses indicadores variam de 0 a 1 , sendo que os valores na casa dos 0,80 e 0,90 , ou superiores, indicam um ajustamento satisfatório.

- A Root-Mean-Square Error of Approximation (RMSEA), com seu intervalo de confiança de 90\% (IC90\%), é considerado um indicador de "bondade" de ajuste, isto é, valores altos indicam um modelo não ajustado. Assume-se como ideal que o RMSEA se situe entre 0,05 e 0,08 , aceitando-se valores até 0,10 .

- O Comparative Fit Index (CFI) - compara de forma geral o modelo estimado ao modelo nulo, considerando valores mais próximos de um como indicadores de ajustamento satisfatório.

- O Normed Fit Index (NFI), varia de zero a um e pode ser considerado aceitável para valores superiores a 0,90. Caracteriza-se por ser uma medida de comparação entre o modelo proposto e o modelo nulo, representando um ajuste incremental. 
- Tucker-Lewis Index (TLI), apresenta uma medida de parcimônia entre os índices do modelo proposto e do modelo nulo. Varia de zero a um, com índice aceitável acima de 0,90.

- O Expected Cross-Validation Index (ECVI) e o Consistent Akaike Information Criterion (CAIC) são indicadores geralmente empregados para avaliar a adequação de um modelo determinado em relação a outro. Valores baixos do ECVI e CAIC expressam o modelo com melhor ajuste. Além destes cálculos, serão realizadas correlação de Pearson, teste t de Student, alfa de Cronbach e qui-quadrado.

\section{Resultados e Discussão}

Finalizada a coleta de dados, as respostas foram inseridas no programa Excell e categorizadas da sua apresentação nominal para intervalar, de acordo com o que era apresentado nos instrumentos da pesquisa no site em que foi hospedado e em seguida digitados na planilha do SPSS 24.0.

Em seguida efetuaram-se as análises sobre a qualidade da amostra, observando que os omissos da pesquisa estiveram abaixo de 5\%, podendo substituí-los pela média ou moda dos dados da amostra, no caso de existir no banco de dados questões duplicadas ou sem respostas; quanto a multicolinearidade entre as variáveis, as correlações entre elas estiveram dentro dos parâmetros definidos por Tabachnick e Fidell (2001) [ $\mathrm{r} \leq 0,90$, variando de 0,10 a 0,77], sendo assim, devido a não existência de variáveis com alto grau de correlação é possível elaborar modelos correlacionais com baixo erro de medida. Por fim, verificou-se também, a presença de outliers multivariados, o qual, foi realizado através do teste de normalidade de Kolmogorov-Smirnov (KS) observando um KS = 0,73 e um p < 0,25 (cf. Nascimento, Tibana, Fereira, \& Prestes, 2014; Miot, 2017).

Nos que se refere as informações sobre a amostra, observaram-se as seguintes: foram 606 mães (a qual, foi distribuída para três etapas do estudo: uma exploratória, outra confirmatória e de convergência), distribuídas em diferentes Estados brasileiros [Rio Grande do Norte (56\%), Paraíba (15\%), São Paulo (13\%), Alagoas (5\%), Pernambuco (4\%), Pará (3\%), Sergipe e Rio de Janeiro (2\%), os Estados (Minas Gerais, Distrito Federal, Santa Catarina, Rio Grande do Sul, tiveram apenas $1 \%$ dos respondentes]. A idade variou de 20 a 72 anos (Média = 38,92, d.p. =7,78), a maioria (67\%) eram casadas, tinha dois filhos (49\%), tendo-lhes a mais de 8 anos (13\%; chama-se atenção que, na distribuição dos demais anos, não ultrapassou os 5\% da amostra). No que se refere a vínculo de trabalho, $82 \%$, tem apenas um vínculo, com $48 \%$ trabalhando os dois horários, com 12,86 anos (d.p. $=7,95$ ) de tempo de serviço.

Considerando que a medida utilizada neste estudo foi desenvolvida a partir de outras escalas que contemplassem o tema da culpa, bem como, por este instrumento apresentar uma originalidade para o contexto da psicologia em geral, pois, nas recentes buscas nos sites da produção científica brasileira na área da psicologia geral, psicologia do desenvolvimento, psicologia do consumo, entre outras áreas (por exemplo, scielo.br, newpsi.bvs-psi.org.br, pepsic.bvsalud.org) não foram encontrados estudos sobre o tema e muito menos, sobre uma escala de medida a respeito do construto psicológico proposta deste estudo.

\section{Estudo 1: Descriminação e representatividade dos itens da escala.}

Considerando a amostra de 202 mães participantes da pesquisa, nesta etapa dos resultados, avaliou-se o poder discriminativo e da representatividade de conteúdo dos itens da escala de culpa sobre o consumo (versão mãe). O objetivo central desta análise tem o foco de apresentar uma maior especificidade na análise estatística destinada a organização e verificação da distribuição dos itens da escala. 
Tendo por base de análise os pressupostos da Teoria Clássica dos Testes (TCT) (cf. Pasquali, 2011; Formiga, Fleury, Fandiño, \& Souza, 2016), nesta etapa, a análise estatística é considerada pelos autores, em termos da sua importância em avaliar se os itens, realmente, são capazes, respectivamente, de discriminar e representar as respostas. Inicialmente, procurou-se avaliar o quanto as pessoas com magnitudes próximas em suas respostas na escala apresentada; isto é, pode-se discriminar as respostas dos sujeitos quando considerar as respostas organizadas nos grupos inferiores e superiores com relação ao construto medido?

Com isso, para atender a etapa da discriminação dos itens da escala, calculou-se a pontuação total desta, seguida da avaliação de sua mediana. Os respondentes com pontuação abaixo da mediana foram classificados como sendo do grupo inferior da medida, enquanto aqueles com pontuações acima da mediana definiu-se de grupo superior (Formiga, Fleury, Fandiño, \& Souza, 2016). Considerando-se cada um dos itens desta medida, efetuou-se um teste t para amostras independentes e compararam-se os grupos observando o quanto cada item da escala discrimina as pessoas com magnitudes próximas estatisticamente significativas (Tabela 1).

Como é possível observar, todos os itens foram significativos, bem como, apresentaram um $t>1,96$, com os escores médios dos itens na categoria superior da medida, podendo afirmar que os respondentes tendem a indicar sempre no ponto superior da escala as suas respostas, o qual, destinado ao grau de concordância. 
Research, Society and Development, v. 10, n. 4, e56110414629, 2021

(CC BY 4.0) | ISSN 2525-3409 | DOI: http://dx.doi.org/10.33448/rsd-v10i4.14629

Tabela 1. Discriminação e representatividade de conteúdo dos itens da ESCC

\begin{tabular}{|c|c|c|c|c|c|c|}
\hline \multirow{2}{*}{ Variáveis/Itens } & \multirow{2}{*}{$\begin{array}{r}\text { Grupo } \\
\text { discriminante }\end{array}$} & \multirow[t]{2}{*}{ Média } & \multirow[t]{2}{*}{ d.p. } & \multicolumn{3}{|c|}{ Estatística } \\
\hline & & & & $\begin{array}{c}t \\
(>1,96)\end{array}$ & $\mathrm{p}$-valor & $\begin{array}{c}\text { ritem-total }_{\text {(Correlação }} \\
\text { Pearson) }\end{array}$ \\
\hline \multirow{2}{*}{$\begin{array}{l}\text { 1. Sinto-me culpada por comprar objetos que } \\
\text { meu (minha) filho (a) não precisa. }\end{array}$} & gi & 0,61 & 1,01 & \multirow{2}{*}{$-7,98$} & \multirow{2}{*}{0,001} & \multirow[t]{2}{*}{0,61} \\
\hline & gs & 2,96 & 1,36 & & & \\
\hline \multirow{2}{*}{$\begin{array}{l}\text { 2. Sinto-me culpada quando tenho inveja das } \\
\text { compras que meus parentes e/ou amigos } \\
\text { muito íntimos fazem para seu (sua) filho (a). }\end{array}$} & gi & 0,25 & 0,60 & \multirow[t]{2}{*}{$-7,68$} & \multirow{2}{*}{0,001} & \multirow{2}{*}{0,61} \\
\hline & gs & 2,18 & 1,45 & & & \\
\hline \multirow{2}{*}{$\begin{array}{l}\text { 3. Quando cedo as promoções pensando no } \\
\text { meu (minha) filho (a), logo em seguida, vem } \\
\text { um sentimento de arrependimento. }\end{array}$} & gi & 0,48 & 0,85 & \multirow{2}{*}{$-6,03$} & \multirow[t]{2}{*}{0,001} & \multirow[t]{2}{*}{0,63} \\
\hline & gs & 2,73 & 1,34 & & & \\
\hline \multirow{2}{*}{$\begin{array}{l}\text { 4. Sinto remorso por ter comprado algo que } \\
\text { não deveria neste momento para meu } \\
\text { (minha) filho (a). }\end{array}$} & gi & 0,50 & 0,80 & \multirow{2}{*}{$-7,92$} & \multirow[t]{2}{*}{0,001} & \multirow[t]{2}{*}{0,71} \\
\hline & gs & 2,05 & 1,54 & & & \\
\hline \multirow{2}{*}{$\begin{array}{l}\text { 5. Desejo ter a vida financeira das pessoas } \\
\text { mais próximas, as quais, têm muito mais } \\
\text { condição econômica do que a minha, por } \\
\text { isso, sinto culpa. }\end{array}$} & gi & 0,27 & 0,79 & \multirow{2}{*}{$-8,98$} & \multirow[t]{2}{*}{0,001} & \multirow[t]{2}{*}{0,60} \\
\hline & gs & 2,51 & 1,53 & & & \\
\hline \multirow{2}{*}{$\begin{array}{l}\text { 6. Quando entro no meu limite do cartão ou } \\
\text { cheque especial para gastar com meu } \\
\text { (minha) filho (a), sinto-me tão culpada. }\end{array}$} & gi & 0,34 & 0,96 & \multirow{2}{*}{$-7,24$} & \multirow[t]{2}{*}{0,001} & \multirow[t]{2}{*}{0,64} \\
\hline & gs & 2,92 & 1,68 & & & \\
\hline \multirow{2}{*}{$\begin{array}{l}\text { 7. Sinto culpa por não ter força de } \\
\text { economizar e realizar meus propósitos de } \\
\text { futuro do meu (minha) filho (a). }\end{array}$} & gi & 0,53 & 0,90 & \multirow{2}{*}{$-8,16$} & & \\
\hline & gs & 3,18 & 1,50 & & 0,001 & 0,62 \\
\hline 8. Geralmente termino o mês gastando mais & gi & 0,09 & 0,32 & & 0,001 & 0,77 \\
\hline $\begin{array}{l}\text { chegando a faltar dinheiro para as despesas } \\
\text { do mês com ele }(a) \text {. }\end{array}$ & gs & 1,35 & 1,37 & $-7,48$ & & \\
\hline $\begin{array}{l}\text { 9. Sinto culpa por comprar por impulso e } \\
\text { sem pensar, pensando somente no meu }\end{array}$ & gi & 0,32 & 0,75 & & & \\
\hline (minha) filho (a). & gs & 2,86 & 1,50 & $-15,1$ & 0,001 & 0,04 \\
\hline 10. Quando vou ao shopping com meu & gi & 1,11 & 1,53 & $-8,96$ & 0,001 & 0,71 \\
\hline (minna) & gs & 2,97 & 1,63 & & & \\
\hline 11. Comprar para meu (minha) filho (a), & gi & 0,44 & 0,91 & -919 & 0,001 & 0,63 \\
\hline alivia as minhas tensões e irritações. & gs & 2,73 & 1,52 & & & \\
\hline 12. Sempre que compro para meu (minha) & gi & 2,78 & 1,73 & $-9,68$ & 0,001 & 0,56 \\
\hline tilho (a), me sinto tão teliz. & gs & 3,72 & 1,44 & & & \\
\hline $\begin{array}{l}\text { 13. Compro para meu (minha) filho (a), } \\
\text { mesmo sem poder, apenas para me sentir }\end{array}$ & gi & 0,10 & 0,45 & $-7,25$ & 0,001 & 0,63 \\
\hline melhor. & gs & 2,09 & 1,29 & & & \\
\hline $\begin{array}{l}\text { 14. Sinto-me culpada por comprar objetos } \\
\text { para meu (minha) filho (a), sabendo que eles }\end{array}$ & gi & 0,36 & 0,83 & $-8,24$ & 0,001 & 0,64 \\
\hline & gs & 2,82 & 1,56 & & & \\
\hline
\end{tabular}

Fonte: Autores. 
Na mesma Tabela 1, é apresentado o resultado da avaliação da representatividade comportamento-domínio; o objetivo desse cálculo destinou-se a verificação da relação teórica-empírica estabelecida para avaliação do sentimento de culpa das mães frente ao consumo, a qual, atribuída às situações especificadas nos itens e o quanto este instrumento representa os aspectos esperados (Cunha, 2000; Pasquali, 2011).

A partir de uma correlação linear de Pearson (r) associando a pontuação total a cada item, tendo hipotetizado a existência de correlações acima de 0,50 entre item-escore total, pode-se destacar que todos eles representaram, significativamente ( $\mathrm{p}<0,001$ ), o binômio comportamento-domínio relacionado ao construto proposto, assumindo um critério de moderado a alto nível correlacional entre variáveis, condição que estabelece a não exclusão de nenhum item da medida pretendida (ver tabela 1). Ciente destas informações, partiu-se para avaliar a distribuição fatorial da referida medida em mães.

\section{Estudo 2: Análise exploratória e de consistência interna da escala.}

A partir dos resultados observados na análise anterior, efetuou-se uma análise fatorial exploratória. Com a segunda amostra, também, de 203 mães, com características sociodemográficas semelhantes a N1. Para isso, estabeleceram-se os seguintes critérios estatísticos (Dancey \& Reidy, 2006): o método dos Componentes Principais (PC), deixando livre o número de fatores a que se pretende extrair, estabelecendo a rotação fatorial oblíqua (oblimin) e assumido saturação de $\pm 0,30$ para a retenção dos fatores.

Com objetivo de ter uma maior segurança na tomada de decisão na escolha dos fatores, também, foi adotado mais outros critérios de avaliação fatorial: (1) quantidade de valores próprios (eigenvalues) iguais ou superiores a 1 (Critério de Kaiser), (2) distribuição gráfica dos valores próprios, tomando como referência o ponto a partir do qual nenhum outro fator aporta consideravelmente para a estrutura (Critério de Cattell) e (3) análise paralela (O’Connor, 2000; Dancey \& Reidy, 2006).

Os resultados da análise fatorial exploratória permitiram identificar a adequação da matriz de correlação: $\mathrm{KMO}=0,88 \mathrm{e}$ do Teste de Esfericidade de Bartlett, $\chi^{2} / \mathrm{gl}=1310,21 / 91, p<0,001$. Na distribuição gráfica tendo como base os valores próprios (critério de Cattell), foram identificados três fatores na escala (ver Figura 1).

Figura 1. Diagrama de declividade do número de fatores plotados da ESCC.

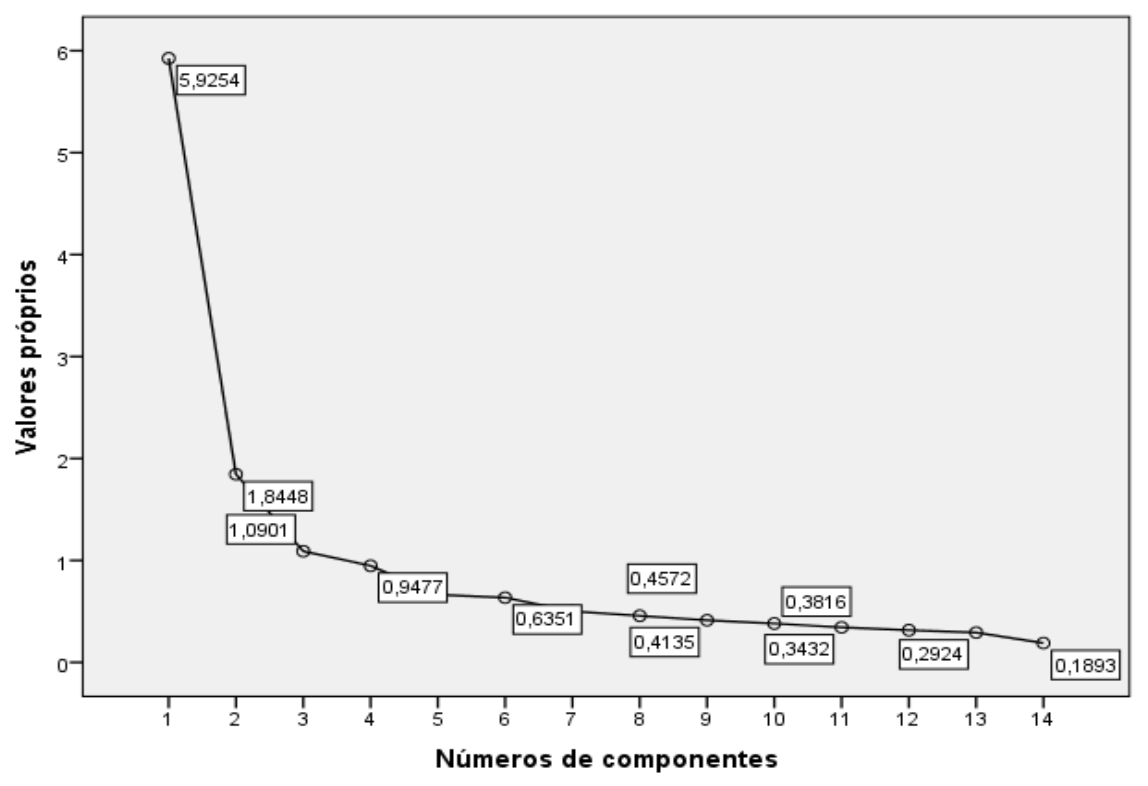

Fonte: Autores. 
De acordo o critério de Kaiser (isto é, os valores próprios - Eigenvalues), identificou-se também, a existência de três fatores com valores próprios maiores que 1 (um), explicando conjuntamente $63,29 \%$ da variância total do fenômeno avaliado. Para evitar dúvidas referente a organização fatorial da escala em questão, realizou-se a análise paralela, assumindo os mesmos parâmetros do banco de dados original. Isto é, 203 participantes e 14 (dez) variáveis-itens, tendo seus valores próprios gerados em 1.000 simulações aleatórias com os itens (Tabela 2).

Tabela 2. Distribuição dos fatores da análise PC de acordo com o critério de Kaiser e análise paralela.

\begin{tabular}{cc}
\hline Critério de Kaiser & Análise paralela \\
\hline $\mathbf{5 , 9 2}$ & $\mathbf{1 , 5 5}$ \\
$\mathbf{1 , 8 4}$ & $\mathbf{1 , 4 2}$ \\
1,09 & 1,32 \\
\hline
\end{tabular}

Fonte: Autores.

Na Tabela 2, comparando os escores dos valores próprios, isto é, aqueles observados nos critérios de Kaiser e na análise paralela, pode-se observar que aqueles encontrados no critério de Kaiser apresentaram valores superiores aos simulados (análise paralela). Identificou-se que a escala é bifatorial, pois, no terceiro fator, o seu valor próprio (eigenvalue) foi menor do que o valor na análise paralela. Atento a interpretação do item-fator, juízes especializados (na estatística e avaliação psicológica) nas análises efetuadas, contribuíram com seu julgamento, corroborando a decisão que se esperava: a bifatorialidade da escala.

A partir desses critérios, procedeu-se a realização de uma análise fatorial do Componentes Principais (PC) com rotação oblíqua, eigenvalue (valor próprio) > 1,00 para definir o fator e saturação de $\pm 0,30$ para retenção dos itens. A utilização desta técnica se mostrou bastante adequada através dos seguintes indicadores: $\mathrm{KMO}=0,88$ e do Teste de Esfericidade de Bartlett, $\chi^{2} / \mathrm{gl}=1310,21 / 91, p<0,001$. Os resultados desta extração fatorial, revelaram a organização de dois fatores, o qual, segue o resultado encontrado nas análises para tomada de decisão - valores próprios (eigenvalues) iguais ou superiores a 1 (Critério de Kaiser), distribuição gráfica dos valores próprios (Critério de Cattell) e a análise paralela.

O primeiro fator, definido como sentimento de culpa por desajuste de ego e impulsividade, conceituando como: capacidade de sentimento de culpa devido à baixa organização do ego e alta impulsividade; este fator, explicou conjuntamente 42,32\% da variância do fator, composto pelos itens (1. Sinto-me culpada por comprar objetos que meu (minha) filho (a) não precisa; 2. Sinto-me culpada quando tenho inveja das compras que meus parentes e/ou amigos muito íntimos fazem para seu (sua) filho (a); 3. Quando cedo as promoções pensando no meu (minha) filho (a), logo em seguida, vem um sentimento de arrependimento; 4. Sinto remorso por ter comprado algo que não deveria neste momento para meu (minha) filho (a); 5 . Desejo ter a vida financeira das pessoas mais próximas, as quais, têm muito mais condição econômica do que a minha, por isso, sinto culpa; 6. Quando entro no meu limite do cartão ou cheque especial para gastar com meu (minha) filho (a), sinto-me tão culpada; 8. Geralmente, término o mês gastando mais do que deveria com meu (minha) filho (a); chegando a faltar dinheiro para as despesas do mês com ele (a); 9. Sinto culpa por comprar por impulso e sem pensar, pensando somente no meu (minha) filho (a); 10. Quando vou ao shopping com meu (minha) filho (a), me sinto melhor; 15. Sempre que compro para meu (minha) filho (a), me sinto tão feliz) (ver Tabela 4).

O segundo fator, categorizado de sentimento de culpa catártica/não consciente, podendo conceituar da seguinte forma: capacidade sentimental de que consome (compra) para o(s) filho(a)(s) para gerar uma 'catarse' emocional e devido a baixa consciência motivacional para compra, explicou $13,18 \%$ e é formado pelos itens (11. Comprar para meu (minha) filho (a), alivia as minhas tensões e irritações; 12. Sempre que compro para meu (minha) filho (a), me sinto tão feliz; 13. Compro para 
meu (minha) filho (a), mesmo sem poder, apenas para me sentir melhor; 14. Sinto-me culpada por comprar objetos para meu (minha) filho (a), sabendo que eles não precisam.) (ver também, Tabela 4).

A fim de facilitar a compreensão do leitor, apresentou-se o conteúdo de cada item, sua saturação (carga fatorial) e comunalidade, os indicadores de consistência interna (Alfa de Cronbach) e variância explicada pelo fator. Assim, todos os indicadores estiveram dentro do padrão psicométrico exigido (Hair et al., 2005; Pasquali, 2011), o que garante a qualidade fatorial da escala ESCC (versão mães).

Tabela 3. Análise dos principais componentes (PC) da ESCC (versão mães).

\begin{tabular}{|c|c|c|c|}
\hline Itens & ai.f1 & aif2 & $\mathbf{h}^{2}$ \\
\hline $\begin{array}{l}\text { ESCC 4. Sinto remorso por ter comprado algo que não deveria neste momento } \\
\text { para meu (minha) filho (a). }\end{array}$ & 0,83 & ---- & 0,50 \\
\hline ESCC 15. Sempre que compro para meu (minha) filho (a), me sinto tão feliz & 0,79 & ---- & 0,43 \\
\hline ESCC 10. Quando vou ao shopping com meu (minha) filho (a), me sinto melhor. & 0,77 & ---- & 0,51 \\
\hline $\begin{array}{l}\text { ESCC 8. Geralmente termino o mês gastando mais do que deveria com meu } \\
\text { (minha) filho (a); chegando a faltar dinheiro para as despesas do mês com ele (a). }\end{array}$ & 0,75 & ---- & 0,73 \\
\hline $\begin{array}{l}\text { ESCC 6. Quando entro no meu limite do cartão ou cheque especial para gastar } \\
\text { com meu (minha) filho (a), sinto-me tão culpada. }\end{array}$ & 0,74 & --- & 0,41 \\
\hline $\begin{array}{l}\text { ESCC 3. quando cedo as promoções pensando no meu (minha) filho (a), logo em } \\
\text { seguida, vem um sentimento de arrependimento. }\end{array}$ & 0,71 & ---- & 0,58 \\
\hline $\begin{array}{l}\text { ESCC 1. sinto-me culpada por comprar objetos que meu (minha) filho (a) não } \\
\text { precisa. }\end{array}$ & 0,70 & ---- & 0,61 \\
\hline $\begin{array}{l}\text { ESCC 2. sinto-me culpada quando tenho inveja das compras que meus parentes } \\
\text { e/ou amigos muito íntimos fazem para seu (sua) filho (a). }\end{array}$ & 0,65 & ---- & 0,45 \\
\hline $\begin{array}{l}\text { ESCC 9. sinto culpa por comprar por impulso e sem pensar, pensando somente } \\
\text { no meu (minha) filho (a). }\end{array}$ & 0,65 & --- & 0,60 \\
\hline $\begin{array}{l}\text { ESCC 5. desejo ter a vida financeira das pessoas mais próximas, as quais, têm } \\
\text { muito mais condição econômica do que a minha, por isso, sinto culpa. }\end{array}$ & 0,60 & ---- & 0,63 \\
\hline $\begin{array}{l}\text { ESCC 11. Comprar para meu (minha) filho (a), alivia as minhas tensões e } \\
\text { irritações. }\end{array}$ & ---- & 0,78 & 0,59 \\
\hline ESCC 12. Sempre que compro para meu (minha) filho (a), me sinto tão feliz & ---- & 0,72 & 0,48 \\
\hline $\begin{array}{l}\text { ESCC 13. compro para meu (minha) filho (a), mesmo sem poder, apenas para me } \\
\text { sentir melhor. }\end{array}$ & ---- & 0,69 & 0,62 \\
\hline $\begin{array}{l}\text { ESCC 14. sinto-me culpada por comprar objetos para meu (minha) filho (a), } \\
\text { sabendo que eles não precisam. }\end{array}$ & ---- & 0,68 & 0,63 \\
\hline Número total de itens & 10 & 04 & 14 \\
\hline Valores próprios & 5,93 & 1,84 & 7,77 \\
\hline Variância explicada & 42,32 & 13,18 & 55,50 \\
\hline Alpha de Chronbach $(\alpha)$ & 0,90 & 0,77 & 0,88 \\
\hline ICC & 0,89 & 0,74 & 0,87 \\
\hline (95\% IC) & $\begin{array}{c}(0,87- \\
0,92)\end{array}$ & $\begin{array}{l}(0,70- \\
0,79)\end{array}$ & $\begin{array}{l}(0,85- \\
0,90)\end{array}$ \\
\hline
\end{tabular}

Nota: $a_{\mathrm{ifl}}=$ itens dimensão culpa por desajuste de ego e impulsividade; $\mathrm{a}_{\mathrm{if} 2}=$ itens dimensão culpa catártica/não consciente; Carga Fatorial; $\mathrm{h}^{2}$ $=$ Cumunalidade. $\mathrm{N}=203$ mães. Fonte: Autores. 
De acordo com os resultados apresenta na tabela 2, estes, garantiram a organização fatorial da ESCC distribuídas em dois fatores (fator 1 - sentimento de culpa por desajuste de ego e impulsividade e fator 2 - sentimento de culpa catártica/não consciente). Com isso, a escala apresentou consistência psicométrica em relação a fatorialidade conteúdo-item-fator; mas, como na análise exploratória, a sua aleatoriedade não permite teorizar sobre um modelo adequado para futuros estudos, desta forma, realizou-se uma segunda pesquisa destinada a análise fatorial confirmatória da ESCC, a qual, apresentada a seguir.

Além desses resultados, avaliou-se também, a relação entre os fatores; para esta etapa estatística, esperava-se que houvesse uma relação positiva e forte entre os fatores da ESCC, bem como, com a pontuação total. Sendo assim, a partir de uma correlação de Pearson, observou-se que o fator sentimento de culpa por desajuste de ego e impulsividade relacionou-se com o fator sentimento de culpa catártica/não consciente $(r=0,48, p<0,001)$ e, também, estes mesmos fatores, com a pontuação total da ESCC (respectivamente, $r=0,84$ e $0,64, p<0,001$ ).

A partir desses resultados, provavelmente, na medida em que algum respondente, apresentar um escore mais alto em um desses fatores, também, terá um alto escore nos demais fatores. Além disso, essas correlações revelam que o sentimento de culpa relacionado ao consumo se apresenta quanto construto convergentes e interdependentes. Desta maneira, observando que a ESCC apresentou uma organização fatorial em dois fatores, os quais destacados acima, realizou-se uma análise estatística a fim de confirmar a consistência dos dois fatores.

\section{Estudo 3. Análise fatorial confirmatória da ESCC}

Nesta etapa do resultado, com base nos indicadores psicométricos da análise fatorial exploratória, efetuou-se o cálculo da análise confirmatória; para isso, empregou-se o pacote estatístico AMOS 24.0, tendo como orientação hipotética a representação de um construto reflexivo, o qual, tem seu núcleo quanto base conceitual associado aos itens, assumindo a organização fatorial apresenta na análise exploratória (ver Figura 2).

Figura 2. Representação do construto reflexivo da ESCC.

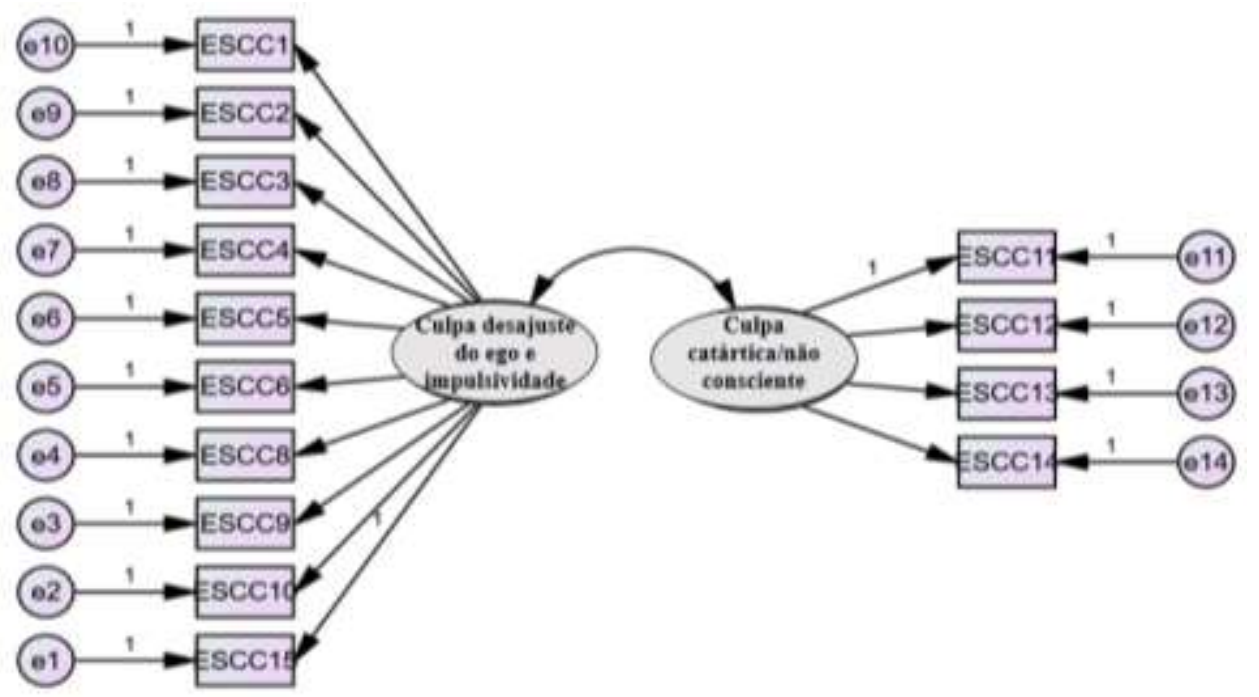

Fonte: Autores.

Uma terceira coleta foi providenciada, destinada a aplicação deste cálculo, esta, apresentou características muito próximas a N1 e N2. Com isso, 211 mães distribuídas em vários Estados brasileiros: Rio Grande do Norte (30\%), Paraíba (27\%), Distrito Federal (14\%), Pernambuco (9\%), Amazonas (5\%), São Paulo (4\%), Ceará e Tocantins (4\%), os demais Estados (Minas Gerais, Rio de Janeiro) tiveram apenas 1\% dos respondentes. 
A idade variou de 23 a 58 anos (Média = 37,47, d.p. =6,27), a maioria (78\%) eram casadas, tinham um filho (52\%), tendo-lhes a mais de 2 anos (27\%; na distribuição total da quantidade de mais de 3 filhos, não ultrapassou $5 \%$ da amostra). No que se refere a vínculo de trabalho, $76 \%$ têm apenas um vínculo, com $49 \%$ trabalhando os dois horários.

Na Figura 1, é possível observar a proposta do modelo bifatorial que se pretende confirmar, previamente observado nos resultados do segundo estudo. Espera-se que a organização item-fator na análise confirmatória, observada na análise fatorial exploratória, apresentem uma associação semelhante.

É preciso destacar, apesar dos resultados observados na análise exploratória serem confiáveis, estes, apresentam uma aleatoriedade, condição que não permite teorizar sobre um modelo adequado que venha confirmar o estudo presente, bem como, seja útil para avaliação em futuros estudos, no qual, item e fator estejam associados de forma positiva e confiável (cf. Formiga, Freire, \& Fernandes, 2019).

Sendo assim, com base numa amostra de 211 mães, com características sociodemográficas semelhantes à da amostra destinada a análise exploratória, realizou-se a Análise Fatorial Confirmatória (AFC). Optou-se por deixar livre as covariâncias (phi, $\varphi$ ), permitindo observar indicadores de qualidade de ajuste para o modelo proposto próximos as recomendações apresentadas na literatura (Byrne, 1989; Tabachnick \& Fidell, 1996; Van De Vijver \& Leung, 1997).

Nestes resultados, o modelo pretendido (modelo bifatorial oblíquo) apresentou indicadores estatísticos que justificam a consistência da estrutura fatorial da ESCC em mães, confirmando, de forma mais robusta a proposta fatorial observada no segundo estudo.

Os indicadores de qualidade de ajuste do modelo se mostraram próximos aos recomendados na literatura (Byrne, 1989; Van de Vijver \& Leung, 1997). Os resultados desta análise podem ser observados, a partir das seguintes razões psicométricas: modelo bifatorial oblíquo $\left[\chi^{2} / \mathrm{gl}=1,50, G F I=0,94, A G F I=0,91, C F I=0,97\right.$, TLI $=0,96, R M S E A(90 \% I C)=0,05(0,03$ $0,07), \mathrm{CAIC}=366,29 \mathrm{e} \mathrm{ECVI}=0,85]$.

Tais indicadores podem ser estabelecidos como os melhores para a proposta da estrutura bifatorial ajustada, quando comparados aos resultados com a medida unifatorial $\left(\chi^{2} / \mathrm{gl}=5,02, G F I=0,75, A G F I=0,66, C F I=0,72, \mathrm{TLI}=0,67, R M S E A\right.$ $(90 \% I C)=0,14(0,12-0,15), \mathrm{CAIC}=564,12$ e ECVI $=2,11)$ e com a medida bifatorial não ajustado $\left(\chi^{2} / \mathrm{gl}=3,63, G F I=0,84\right.$, $A G F I=0,77, C F I=0,82, \mathrm{TLI}=0,79, \operatorname{RMSEA}(90 \% I C)=0,11(0,10-0,13), \mathrm{CAIC}=460,10 \mathrm{e}$ ECVI $=1,59)($ ver Tabela 4$)$.

Tabela 4. Indicadores psicométricos da comparação da estrutura fatorial da escala ESCC.

\begin{tabular}{|c|c|c|c|c|c|c|c|c|}
\hline \multirow[b]{2}{*}{ Modelos } & \multicolumn{4}{|c|}{ Medidas de ajuste incremental } & \multicolumn{2}{|c|}{$\begin{array}{l}\text { Medidas de ajuste } \\
\text { parcimonioso }\end{array}$} & \multicolumn{2}{|c|}{$\begin{array}{l}\text { Medidas de ajuste } \\
\text { parcimonioso }\end{array}$} \\
\hline & $\chi^{2} / \mathrm{gl}$ & GFI & AGFI & CFI & TLI & $\begin{array}{l}\text { RMSEA } \\
\text { (intervalo) }\end{array}$ & CAIC & $\begin{array}{c}\text { ECVI } \\
\text { (invervalo) }\end{array}$ \\
\hline Unifatorial & 5,02 & 0,75 & 0,66 & 0,72 & 0,67 & $\begin{array}{c}0,14 \\
(0,12-0,15\end{array}$ & 564,12 & $\begin{array}{c}2,11 \\
(1,83-2,42)\end{array}$ \\
\hline $\begin{array}{l}\text { 2F } \\
\text { Oblíquos } \\
\text { não justado }\end{array}$ & 3,63 & 0,83 & 0,77 & 0,82 & 0,79 & $\begin{array}{c}0,11 \\
(0,10-0,13)\end{array}$ & 460,10 & $\begin{array}{c}1,59 \\
(1,37-1,85)\end{array}$ \\
\hline $\begin{array}{l}2 \mathrm{~F} \\
\text { Oblíquos } \\
\text { ajustado }\end{array}$ & 1,50 & 0,94 & 0,91 & 0,97 & 0,96 & $\begin{array}{c}0,05 \\
(0,02-0,06)\end{array}$ & 366,29 & $\begin{array}{c}0,85 \\
(0,75-1,00)\end{array}$ \\
\hline
\end{tabular}


Além destes indicadores psicométricos apresentados na Tabela 4, outros, com aspectos mais parcimoniosos (por exemplo, o AIC, BIC e BCC), garantiram o modelo bifatorial não ajustado. Tais indicadores acompanham o CAIC e ECVI, os quais, são utilizados para avaliar a adequação de um modelo determinado em relação a outros modelos para comparação fatorial (neste caso, a proposta do modelo bifatorial oblíquo ajustado em relação aos demais modelos) para verificar a melhor estrutura fatorial (Marôco, Tecedeiro, Martins, \& Meireles, 2008). Como observado na Tabela 5, os melhores indicadores estiveram para o modelo bifatorial oblíquo ajustado, corroborando a bi-fatorialidade.

Tabela 5. Indicadores psicométricos de parcimônia para a comparação da estrutura fatorial da escala ESCC.

\begin{tabular}{lccc}
\hline \multirow{2}{*}{ Modelos } & \multicolumn{2}{c}{ Indicador de parcimônia } \\
& AIC & BIC & BCC \\
\hline Unifatorial & 442,27 & 536,12 & 446,58 \\
2F não ajustado & 33,89 & 431,10 & 338,36 \\
2F ajustado & Oblíquos & \\
& 179,16 & 561,94 & 185,77 \\
& Oblíquos \\
\hline
\end{tabular}

Fonte: Autores.

Observaram-se que todas as saturações (Lambdas, $\lambda$ ) estiveram dentro do intervalo esperado $\mid 0$ - 1|, condição essa, que sugere não haver problemas da estimação proposta da escala em questão (ver Figura 3). Destaca-se também, que todas as saturações foram estatisticamente diferentes de zero $(t>1,96, p<0,05)$ comprovando a existência do modelo bifatorial obliquo, revelando uma associação Phi $(\Phi)$, positiva e forte, entre os fatores sentimento de culpa por desajuste de ego e impulsividade (sentculp1) e sentimento de culpa catártica/não consciente (sentculp2) $(\Phi=0,41)$ (ver Figura 2). A partir de tais resultados, provavelmente, o sujeito ao pontuar escores mais alto em uma dimensão, também, pontuará alto na outra dimensão.

Figura 3. Representação gráfica da estrutura fatorial da ESCCM.

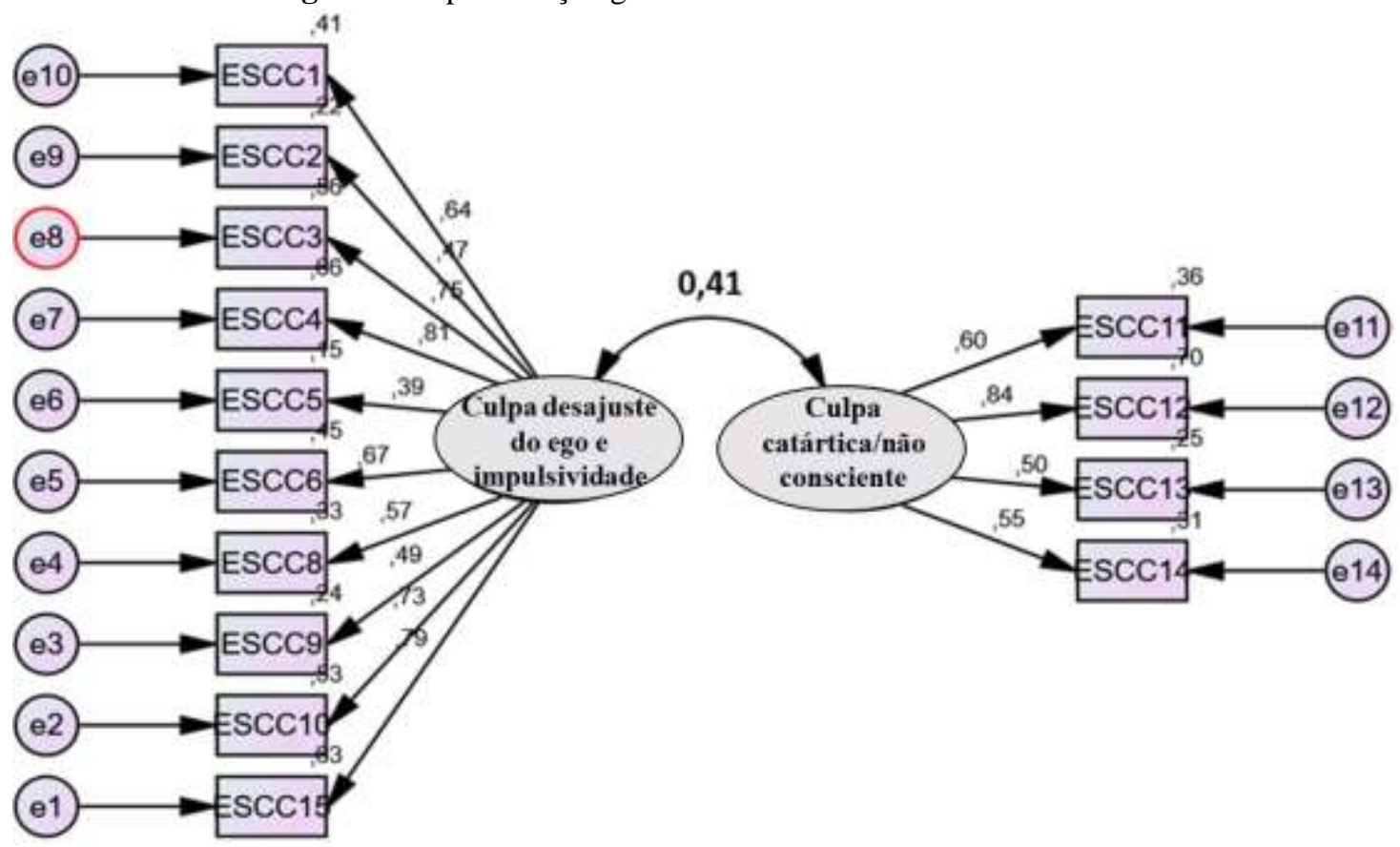

Fonte: Autores. 
Em relação a validade do construto em questão, efetuou-se tanto o cálculo de confiabilidade composta (CC) quanto da variância média extraída (VME); no primeiro indicador exige-se que o nível do escore seja acima de 0.70, enquanto no segundo indicador é preciso um nível acima de 0.50 (Hair, Tatham, Anderson, \& Black, 2005; Campara, Tavares, \& Silva, 2009).

Observou-se que para cada dimensão, o CC e o VME, estiveram acima do exigido na literatura, respectivamente, $0,83 \mathrm{e}$ 0,58. Estes indicadores evidenciam tanto a confiabilidade quanto a validade convergente do construto avaliado, justificando a adequabilidade da estrutura fatorial da pretensa medida numa amostra de mães brasileiras.

Esses resultados foram confirmados quando se observaram as estimativas de predição, a partir da análise de regressão, a qual, revelou para o modelo proposto, a partir da identificação das variáveis, uma razão critério que, além de estarem dentro do que é estatisticamente exigido e estatisticamente diferentes de zero $(t>1,96, p<0,05)$, foram significativas (ver Tabela 4).

Tabela 6. Indicadores das estimativas preditivas da associação itens-fator da ESCC.

\begin{tabular}{lcccccc}
\hline \multicolumn{1}{c}{ Itens } & $<---$ & construto & Estimativa & d.p. & $\begin{array}{c}\text { Razão } \\
\text { Critério }\end{array}$ & $\mathrm{p}<$ \\
\hline ESCC15 & $<---$ & sentculp1 & 1,000 & --- & --- & --- \\
ESCC10 & $<---$ & sentculp1 & 0,936 & 0,082 & 11,346 & 0,001 \\
ESCC9 & $<---$ & sentculp1 & 0,537 & 0,077 & 6,938 & 0,001 \\
ESCC8 & $<---$ & sentculp1 & 0,836 & 0,097 & 8,651 & 0,001 \\
ESCC6 & $<---$ & sentculp1 & 0,887 & 0,088 & 10,104 & 0,001 \\
ESCC5 & $<---$ & sentculp1 & 0,444 & 0,091 & 4,899 & 0,001 \\
ESCC4 & $<---$ & sentculp1 & 0,990 & 0,079 & 12,506 & 0,001 \\
ESCC3 & $<---$ & sentculp1 & 0,849 & 0,074 & 11,470 & 0,001 \\
ESCC2 & $<---$ & sentculp1 & 0,479 & 0,082 & 5,832 & 0,001 \\
ESCC1 & $<---$ & sentculp1 & 0,722 & 0,081 & 8,943 & 0,001 \\
ESCC11 & $<---$ & sentculp2 & 1,000 & --- & -- & -- \\
ESCC12 & $<---$ & sentculp2 & 1,592 & 0,236 & 6,737 & 0,001 \\
ESCC13 & $<---$ & sentculp2 & 0,894 & 0,155 & 5,750 & 0,001 \\
ESCC14 & $<---$ & sentculp2 & 0,551 & 0,095 & 5,779 & 0,001 \\
\hline
\end{tabular}

Fonte: Autores.

Com base nestes resultados, verificou-se a invariância entre os parâmetros dos itens em função da estrutura bifatorial oblíqua ajustada na mensuração do sentimento de culpa da mãe frente ao consumo. Para isso, compararam-se os indicadores TLI e CFI do modelo comprovado espelhando a dois conjuntos amostrais (amostra N1 e amostra N2) (Damásio, 2013; Sass, 2011; Moroco, 2010; Hair, Anderson, Tatham, \& Black, 2005) e observaram-se as seguintes reduções no valor de CFI (a qual espera-se que a diferença seja $\Delta<0,01$, para garantir a estrutura bifatorial nos grupos especificados): $\mathrm{CFI}_{\text {total }}=0,98, \mathrm{CFI}_{\mathrm{N} 1}=$ 0,97 e $\mathrm{CFI}_{\mathrm{N} 2}=0,97$ e TLI total $=0,96, \mathrm{TLI}_{\mathrm{N} 1}=0,96$ e TLI $\mathrm{T}_{\mathrm{N} 2}=0,97$. Pode-se destacar que tais indicadores revelaram que o modelo bifatorial e seus devidos escores fatoriais são invariantes com base nas amostras. 


\section{Estudo 3. Validade convergente da ESCC.}

Pretendendo atender ao objetivo sobre a validade convergente, uma terceira amostra, com 201 mães, com características próximas as amostras anteriores. Desta maneira, com a garantia das fatorialidade na etapa exploratória e confirmatória, verificou-se a validade convergente e divergente desta medida associando-a ao construto da auto-estima, medida, a qual, desenvolvida por Rosemberg (1965), o qual referiu este a um sentimento em relação a si mesmo, que poderá ser positivo ou negativo, avaliado pelo próprio respondente através da auto-avaliação das próprias características deste.

No Brasil, este construto vem sendo utilizado em diversos estudos, bem como, tem apresentado indiciadores psicométricos que permite afirmar a qualidade estrutural da medida de auto-estima em vários grupos etários (jovens, adultos e idosos) (Marriel et al., 2006; Peixoto, 2004; Assis \& Pereira, 2005; Santos \& Maia, 1999; Hutz, 2000; Giacomoni, 2002; Sbicigo, Bandeira e Dell'Aglio, 2010; Gomes, Tolentino, Maia, Formiga, \& Melo, 2016).

Porém, antes de verificar essa relação e, por ser uma medida psicológica de caráter original, optou em avaliar com esta nova amostra, a consistência da estrutura fatorial. No programa AMOS 24, realizou-se tal cálculo e com base nos resultados observados no estudo 1 com a N1 e 2 com a N2, observaram-se os seguintes indicadores psicométricos: $\chi^{2} / \mathrm{gl}=1,66$, $G F I=0,93 A G F I=0,90, C F I=0,96, \mathrm{TLI}=0,95, R M S E A(90 \% I C)=0,05(0,04-0,08), \mathrm{CAIC}=346,16$ e ECVI $=0,94$.

Neste modelo estrutural, as saturações (Lambdas, $\lambda$ ) estiveram intervalo esperado, com todas, estatisticamente, diferentes de zero, tendo uma associação Phi $(\Phi)$ positiva entre os fatores sentimento de culpa por desajuste de ego e $\underline{\text { impulsividade e sentimento de culpa catártica/não consciente }}(\Phi=0,54)$.

Também, observou-se que o CC e o VME foram respectivamente, para o sentimento de culpa por desajuste de ego e $\underline{\text { impulsividade }} 0,86$ e 0,60 e para o sentimento de culpa catártica/não consciente 0,85 e 0,57. Considerando estes indicadores, pode-se afirmar que continuam confiáveis e validos na amostra de mães brasileiras.

A partir desses resultados, realizou-se uma correlação de Pearson entre as variáveis em questão (a ESCCpontuação total e seus fatores com a autoestima e seus fatores). Desta maneira, hipotetizava-se uma relação positiva a ESCC e a autoestima negativa, mas, com a autoestima positiva espera-se uma correlação inversa.

Desta maneira, os resultados foram os seguintes: apenas o sentimento de culpa catártica/não consciente (fator 2) relacionou-se positiva e significativamente, com a autoestima negativa $(\mathrm{r}=0,26, \mathrm{p}<0,01)$; por outro lado, a autoestima positiva, relacionou-se, negativamente, com o sentimento de culpa por desajuste de ego e impulsividade $(r=-0,26$, $\mathrm{p}<0,01)$ e o sentimento de culpa catártica/não consciente $(r=-0,27, \mathrm{p}<0,01)$.

Esses resultados, não apenas confirmam a segurança da medida, mas também, que este construto tem uma influência bem direta da autoestima, especialmente, no que se refere ao tipo deste construto; se tem uma autoestima negativa provavelmente, o processo da culpa seria estimulado, enquanto a autoestima positiva, poderia inibir este processo.

Este artigo teve como objetivo construir e validar uma escala de medida psicológica sobre a culpa de mães frente ao consumo para seus filhos, medida a falta de tempo que elas não têm para ter atenção com eles. É preciso esclarecer que, numa consulta inicial nas bases de dados da produção científica brasileira, não encontrou estudos que focasse neste tema e, em especial, na proposta deste estudo. Com isso, esta pesquisa, por sua vez, teve como orientação alguns estudos sobre a culpa, mas, não a culpa referente ao consumo.

Com a garantia do conteúdo, os quais, expressos no estudo de Formiga, Castro, Gadelha \& Pimentel (2020), a respeito do conteúdo da escala, realizaram-se as análises de discriminação e representatividade de conteúdo; diferente da análise estatística efetuados pelos autores supracitados, esta, é importante para verificar se aqueles respondentes que responderam no ponto próximo a discordância ou concordância, de fato, responderam com honestidade e atenção, bem como, o conteúdo dos itens estão positivamente, relacionados ao que teoricamente esperava. Sendo assim, para todos esses 14 itens é possível afirmar que os respondentes reconheceram e indicaram a existência do construto. 
Definido o construto com base na TCT, realizou-se a análise fatorial; nesta, procurou-se verificar a organização fatorial da escala em questão. A partir dessa análise, observou-se que a medida proposta sobre o sentimento de culpa da mãe relativo ao consumo, se distribuiu em dois fatores; um referindo a culpa devido ao desajuste do ego e impulsividade e o segundo, referia-se a culpa catártica/não consciente. Ambas estão relacionadas a organização emocional, porém, enquanto a primeira foca na desorganização do ego, a segunda tem um sentido de descarga emocional.

Esta organização fatorial, precisou ser confirmada; assim, a análise fatorial confirmatória revelou que não apenas esses fatores fazem parte de uma estrutura fatorial confiável, bem como, a relação entre os fatores é positiva. As duas dimensões de culpa ocorrem de forma interdependentes.

É preciso destacar que, tal estrutura fatorial, independe do tipo de amostra de mães, pois, ao comparar a primeira e a segunda amostra, os indicadores TLI e CFI revelaram valores que confirmam a manutenção da fatorialidade.

Concebida a escala, bem como, a sua qualidade conceitual e fatorial, procurar avaliar se tal construto teria uma função psicológica; com isso, associou-se ao construto da autoestima (positiva e negativa), observando que a mão que for capaz de desenvolver uma autoestima positiva, é capa de organizar melhor a sua cognição.

Condição essa que não é possível ocorrer com aquela mãe que venha apresentar uma autoestima negativa. Esta, por sua vez, teria uma relação direta com ambas a formas de culpa. Ao considerar esses resultados, é possível afirmar que a escal a apresenta indicadores psicométricos que garante a qualidade de uma medida do sentimento de culpa em mães frente ao consumo. Não se trata apenas de um instrumento psicológico, mas, de sugestão de uma avaliação cognitiva de como as mães se apresentam diante das exigências da sociedade de consumo, podendo ser definido quanto um problema de organização egóica.

Ao propor tal medida e apresentá-la quanto caminho avaliativo dos conflitos maternos na relação mãe-filho, principalmente, quando as mães elaboram possíveis compensações atributivas devido ao 'distanciamento' ou baixa qualidade de respostas afetivas ou interação social com os filhos; busca-se uma direção avaliada preditiva destas mães, no momento do rapport psicológico, para a orientação terapêutica.

É possível que tais situações possam não ser claras para as mães, até porque, no sistema cognitivo de todo ser humano, frente as tomadas de decisão, gera uma espécie de economia cognitiva, a qual, a organização e estruturação cognitiva tende sempre para o mais simples e menos complexo (cf. Neves, 2006; Rosa, Scholten, \& Carrilho, 2006; Ranhel, 2011).

Com isso, a proposta dessa medida é agir quanto princípio avaliativo primário do processo terapêutico, bem como, contribuir para a reflexão de que é possível intervir na relação mãe-filho e que a qualidade atenção-afeto é muito mais do que um produto de consumo, trata-se de um reconhecimento, que não são os outros os culpados, mas, a forma e estrutura que uma mãe organiza seu mundo compensatório.

\section{Considerações Finais}

Em termos gerais, os resultados apresentados neste estudo, evidenciaram não apenas a qualidade de uma medida sobre sentimento de culpa no consumo destinados aos filhos, bem como, que é possível administrá-la nos contextos terapêuticos e sociais. Com isso, frente aos indicadores psicométricos, a referida escala é capaz de verificar os fatores psicológicos do fenômeno destacado.

Apesar de considerar que os resultados revelaram indicadores psicométricos aceitáveis, alcançando os objetivos pretendidos, acredita-se que em estudos futuros poderia ser útil avaliar a relação dessa escala em mães no contexto clínicoterapêutico e aquelas sem contexto clínico; outra variável, a qual, sugere muito impacto, seria a realização da avaliação do bem-estar subjetivo e do transtorno emocional (ansiedade, depressão e estresse), sendo ambas as medidas, adaptadas para o contexto materno. 


\section{Referências}

Alexandre, N. M. C., \& Coluci, M. Z. O. (2011). Validade de conteúdo nos processos de construção e adaptação de instrumentos de medidas. Ciência \& Saúde Coletiva, 16(7), 3061-3068.

Armstrong, J. \& Overton, Terry. (1977). Estimating Non Response Bias Mail Surveys. Journal of Marketing Research. 14. $396-402.10 .2307 / 3150783$.

Arteiro, I. L. (2017). A mulher e a maternidade: Um exercício de reinvenção. Tese (Doutorado). Universidade Católica de Pernambuco.

Brasil. Conselho Nacional de Saúde. Resolução 466/12. Trata de pesquisas em seres humanos e atualiza a resolução 196. [Intern et]..

Byrne, B. M, Shavelson, R. J. \& Muthén, B. (1989). Teste de equivalência de covariância fatorial e estruturas médias: A questão da invariância parcial de medição. Psychological Bulletin, 105 (3), 456-466.

Campara, J. P., Vieira, K.M. \& Ceretta, P. S. (2016). Entendendo a atitude ao endividamento: fatores comportamentais e variáveis socioeconômicas o determinam? Revista Eletrônica de Ciência Administrativa, Curitiba, 15(1), 5-24.

Conselho Nacional de Saúde. Resolução no 196/1996. Trata das diretrizes e normas regulamentadoras da pesquisa envolvendo seres humanos. [Internet].

Cunha, Euclides Da. Diário de uma expedição. Cia. das Letras.

Damásio, B. F. (2013) Uso da análise fatorial exploratória em psicologia. Avaliação psicológica. 11(2).

Dancey, CP, Reidy, J. (2004). Estatística sem matemática para psicologia usando SPSS para Windows (3a ed). Pearson Prentice Hall.

Erikson, E. H. (1976a). Infância e sociedade. Zahar.

Erikson, E. H. (1976b). Identidade, juventude e crise. Zahar.

Formiga, N. S., Castro, N. S., Gadelha, J. C., \& Pimentel, L. B. (2020). Escala de Sentimento de Culpa do Consumo (ESCC): desenvolvimento e validade de conteúdo de uma medida psicológica em mães brasileiras. Research, Society and Development, 9(4), e43942814. https://doi.org/10.33448/rsd-v9i4.2814

Formiga, N. S., Fleury, L. F. O., Fandino, A., \& Souza, M. A. (2016) Empirical evidence of an organizational anomie the measure in brazilian workers. Revista de Psicología da UCV, 18(1), 134-149.

Ghingold, M. (1981), Guilt Arousing Marketing Communications: an Unexplored Variable, em NA - Advances in Consumer Research.. Kent B. Monroe, Ann Abor, MI: Association for Consumer Research, 442-448.

Giacomoni, C. H., \& Hutz, C. S. (2006). Escala de afeto positivo e negativo para crianças: estudos de construção e validação. Psicologia Escolar e Educacional, 10(2), 235-245. https://doi.org/10.1590/S1413-85572006000200007

Gomes, M. C. S., Tolentino, T. M., Maia, M. F. M., Formiga, N. S., \&Melo, G. F. (2016). Verificação de um modelo teórico entre bem-estar subjetivo e autoestima em idosos brasileiros. R. bras. Ci. e Mov, 24(2):35-44.

Hair, J. F., Tatham, R. L., Anderson, R. E., \& Black, W. (2005). Análise Multivariada de dados. Bookman.

Hutz, C. S. (2000). Adaptação da escala de autoestima de Rosenberg. Manuscrito não publicado. Universidade Federal do Rio Grande do Sul. Porto Alegre, RS.

Lascu, D. N. (1991). Consumer Guilt: Examining the Potential of a New Marketing Construct. Construct. Advances in consumer research, 18.

Ledesma, R. D. \& Valero-Mora, P. (2007) Determinando o Número de Fatores a Reter na EFA: Um programa de computador fácil de usar para realizar Análise Paralela, Avaliação Prática, Pesquisa e Avaliação, 12(2).

Lima, D. M. (2012). Sobre o sentimento de culpa. Que culpa é essa? About guilt. What fault is that? Estudos de Psicanálise, 53-58.

Maroco, J. (2010). Análise de equações estruturais: Fundamentos teóricos, software \& aplicações. Pêro Pinheiro: Report Number.

Marôco, J., Tecedeiro, M., Martins, P. \& Meireles, A (2008). O Burnout como fator hierárquico de $2^{\mathrm{a}}$ ordem da Escala de Burnout de Maslach. Instituto Superior de Psicologia Aplicada. 26(4), 639-649.

Marriel, L. C., Assis, S. G., Avanci, J. Q. \& Oliveira, R. V. C. (2006) Violência escolar e auto-estima de adolescentes. Cad. Pesqui. [online]., 36(127), 35-50.

Miles, J. N. V. \& Shevlin, M. E. (2001). Applying regression and correlation: a guide for students and researchers. Sage.

Miot, H. A. (2017). Avaliação da normalidade dos dados em estudos clínicos e experimentais. Jornal Vascular Brasileiro, 16 (2), 88-91

Nascimento, D. C., Tibana R. A., Ferreira, G. M., \& Prestes, J. (2014) Testes de normalidade em análises estatísticas: uma orie ntação para praticantes em ciências da saúde e atividade física. Revista Mackenzie de Educação Física e Esporte, 14(2), 73-77.

Neder, M. (2016) Os filhos da mãe: Como viver a maternidade sem culpa e sem o mito da perfeição. Casa da Palavra.

Neves, D. A. (2006). Ciência da informação e cognição humana: uma abordagem do processamento da informação. Ciência da Informação, 35(1), 3944. https://doi.org/10.1590/S0100-19652006000100005

O’Connor, R. J. (2000) Why ecology lags behind biology. Scientist, 14(20), 35-35. 
Research, Society and Development, v. 10, n. 4, e56110414629, 2021

(CC BY 4.0) | ISSN 2525-3409 | DOI: http://dx.doi.org/10.33448/rsd-v10i4.14629

Pasquali L. (2011). Psicometria: teoria dos testes na psicologia e na educacão. (4a ed.), Vozes, 2011.

Peixoto, C. E. (2004). Aposentadoria: retorno ao trabalho e solidariedade familiar. Em C. E. Peixoto (Org.). Família e envelhecimento. (pp. 57-84), FGV, (Coleção Família, geração e cultura).

Podsakoff, P. M., Ahearne, M., \& Mackenzie, S. B. (1997). Organizational citizenship behavior and the quantity and quality of work group performance. Journal of Applied Psychology, 82(2), 262-270.

Pontes, K. D. (2012). De menina à mãe: relaçães entre história de vida materna e vínculo afetivo mãe-filho. Dissertação (Mestrado em Psicologia) Universidade Federal do Amazonas.

Ranhel, J. (2011). Princípios para processos cognitivos. Revista digital de tecnologias cognitivas, 5 (2), 30-38.

Rosa, I. V., Scholten, M., \& Carrilho, J. P. (2006). Festinger revisitado: Sacrifício e argumentação como fontes de conflito na tomada de decisão. Análise Psicológica, 24(2), 167-177.

Rosemberg, M. (1965). Society and the adolescent selt-ima. Prínceton, N. J. Princeton University Press.

Sass, D. A. (2011). Testing measurement invariance and comparing latent factor means within a confirmatory factor analysis framework. Journal of Psychoeducational Assessment, 29(4), 347-363.

Sbicigo, J. B., Teixeira, M. A. P., Dias, A. C. G., \& Dell'Aglio, D. D. (2012). Propriedades Psicométricas da Escala de Autoeficácia Geral Percebida (EAGP). Psico, 43(2).

Tabachnick, B., \& Fidell, L. (2001). Using multivariate statistics. Needham Heights: Allyn \& Bacon.

Tourinho, J. G. (2006) A mãe perfeita: idealização e realidade - Algumas reflexões sobre a maternidade. IGT na rede, 33.

Van de Vijver, F., \& Leung, K. (1997). Métodos e análise de dados de pesquisas comparativas. Em JW Berry, YH Poortinga, \& J. Pandey (Eds.), Handbook of cross-cultural psychology ( $2^{\mathrm{a}}$ ed.). Handbook of cross-cultural psychology: Theory and method (p. 257-300). Allyn \& Bacon

Winnicott, D. W. (1982). A criança e seu mundo. Livros Técnicos e Científicos Ed. (Trabalho original publicado em 1964, respeitando-se a classificação de Huljmand temos 1964a)

Winnicott, D. W. (1999). Tudo começa em casa. Martins Fontes. (Trabalho original publicado em 1986, respeitando-se a classificação de Huljmand temos 1986b)

Zanello, V. (2016) Dispositivo materno e processos de subjetivação: desafios para a Psicologia. In: Zanello, V., \& Porto, M. (Orgs.). Aborto e (Não) Desejo de Maternidade(s): questões para a Psicologia. Conselho Federal de Psicologia. Brasília: CFP. 